\title{
O uso do material cômico na tragédia de Shakespeare e seus contemporâneos*
}

\author{
Tiago Marques Luiz ${ }^{*}$ \\ iD https:// orcid.org/0000-0003-4462-3050
}

\author{
Recebido em: 16/06/2018 \\ Aceito para publicação em: 16/11/2018
}

\begin{abstract}
RESUMO: Este artigo tece reflexões acerca da presença da figura do bobo, cuja cenas cômicas são recorrentes em textos trágicos, tanto de Shakespeare como de seus predecessores e contemporâneos, a pontos destes textos serem, por sugestão pelo autor, denominados tragicomédia ou comitragédia. O estudioso propõe grupos de tipos de passagens cômicas dentro das peças renascentistas, ressaltando que Shakespeare é o grande expoente do uso da comicidade em suas peças trágicas, porém, em perspectiva cronológica, Alden expõe como o riso, visto como a consequência da comicidade em detrimento das ações dos bobos, perpassou por autores predecessores e contemporâneos a Shakespeare.
\end{abstract}

Palavras-chave: Elemento Cômico. Tragédia shakespeariana. Bobo. Riso

\begin{abstract}
This article reflects on the presence of the figure of the clown, whose comic scenes are recurrent in tragic texts, as well Shakespeare as his predecessors and contemporaries, to get to the point these texts, by the author's suggestion, call tragicomedy or comitragedy. The scholar proposes groups of types of comic passages within Renaissance plays, emphasizing that Shakespeare is the great exponent of the use of comicity in his tragic plays, however, in chronological perspective, Alden exposes how laughter, seen as the consequence of comedy in detriment of the clowns' actions, is crossed by authors predecessors and contemporaries to Shakespeare.
\end{abstract}

Keywords: Comic element. Shakespearean Tragedy. Clown. Laughter

\footnotetext{
* Esta é uma tradução do artigo "The Use of Comic Material in the Tragedy of Shakespeare and His Contemporaries" de Raymond Macdonald Alden (1873-1924), publicado em 1914 no The Journal of English and German Philology, cuja referência complete se encontra ao final desta tradução. Em relação ao texto original, as notas de rodapé mencionam os nomes das obras citadas, com as devidas páginas. Manteve-se este estilo adotado na tradução, acrescentando a citação na língua de partida. Em caso de tradução de peças teatrais com tradução para o português ou espanhol, estas serão mencionadas tanto no corpo do texto, como também nas próprias notas e referências. Sobre os atos e cenas das referidas peças, o autor menciona o ato em algarismo romano maiúsculo e a cena em algarismo romano minúsculo. Para a tradução, foi usada a indicação por extenso. Por exemplo: II, ii (no original), e na tradução ficou Ato II, Cena II.

* Doutorando em Letras, com área de concentração em Estudos Literários na Universidade Federal de Uberlândia. E-mail: markx2006@gmail.com.
} 
Faz parte dos lugares-comuns na crítica que o tempo do drama de Shakespeare é caracterizado pela mistura do material sério com o cômico de uma maneira bastante peculiar. E uma opinião prevalente de forma muito ampla trata o próprio Shakespeare como representante desta mistura romântica quase em sua forma extrema. A afirmação do Dr. Johnson pode ser considerada típica, na qual todas as peças de Shakespeare são "um intercâmbio de seriedade e alegria1" e que "na tragédia ele está sempre lutando, depois de alguma ocasião, para ser cômico 2". A este entrelaçamento de detalhes cômicos e sérios, os críticos dos séculos XVII e XVIII deram o nome de tragicomédia, confundindo-o com a prática bastante diferente de misturar duas tramas de características contrastantes, ou a aquela ainda diferente de trazer uma situação aparentemente trágica para uma conclusão feliz. Muitas vezes é difícil dizer apenas que tipo de falha romântica está em questão. Whetstone (no prefácio a Promos and Cassandra, 1578), faz objeção àqueles "que criam uma companhia de bobos com um rei3"; Milton (no prefácio a Samson Agonistes, 1671) condena "o erro de combinar material cômico com gravidade e seriedade trágicas, ou introduzir pessoas triviais e vulgares $4^{\prime \prime}$; Rymer (Tragedies of the Last Age, 1678) alude severamente aos "bufões" 5 ", que "realizam um tipo de interlúdio" na tragédia Elizabetana6; Dryden (no prefácio a The Spanish Friar, 1681) fala de tragédias que são "iluminadas com um curso de alegria"”; Addison (Spectator, $\mathrm{n}^{\circ} 40,1711$ ) descreve sob o termo "tragicomédia" o tipo de peça que é "uma peça heterogênea de regozijo e tristeza ${ }^{8 "}$; e Hawkesworth (no prólogo para o reescrito Oronooko, 1759) acusa Southerne de ter "combinado o coturno com a sandália 9 " e por ter manchado "com irreverente alegria [...] a página sagrada 10 " da tragédia ${ }^{11}$. Obviamente estes vários críticos tinham em mente os dramas dos mais variados tipos, tais quais - em um extremo, aqueles predominantemente trágicos,

\footnotetext{
1 Prefácio a Shakespeare; Works, ed. 1801, ii, p. 87. (Original em inglês: "an interchange of seriousness and merriment").

2 Prefácio a Shakespeare; Works, ed. 1801, ii, p. 88. (Original em inglês: "in tragedy he is always struggling after some occasion to be comic").

${ }^{3}$ Elizabethan Critical Essays (ed. Gregory Smith), i, p. 59. Original em inglês: "make a clown companion with a king".

${ }^{4}$ Original em inglês: "error of intermixing comic stuff with tragic sadness and gravity, or introducing trivial and vulgar persons"

${ }^{5}$ Original em inglês: "drolls".

${ }^{6}$ Critical Essays of the 17 $17^{\text {th }}$ Century, ed. Spingarn, ii, p. 206.

7 Essays, ed. W. P. Ker, i, 249.

8 Original em inglês: "a motley piece of mirth and sorrow".

9 Original em inglês: "joined the buskin and the sock". Nota do Tradutor: O coturno era um símbolo usado por atores atenienses que encenavam as peças trágicas, para realçar a dimensão da personagem interpretada, enquanto que a sandália era o símbolo da comédia, por ser de tamanho baixo. A tradução literal seria sapato, porém em português, por uma construção cultural, virou sandália. Agradeço aos professores Thissiane Fioreto (UFGD) e Thiago César Viana Lopes Saltarelli (UFU), pela disponibilidade e clareza de informações. A expressão "sock and buskin" designa os "espíritos" da tragédia e da comédia a partir da simbologia dos calçados. Sock vem do Grego sykkhos, Latim soccus; designa um calçado com solado alto e grosseiro, tão usado pelos atores cômicos gregos que passou a ser considerado o seu símbolo. Um termo equivalente seria o tamanco. ${ }^{10}$ Original em inglês: "with ribald mirth [...] the sacred page".

11 Para outros comentários sobre o mesmo assunto, consulte a obra Shakespeare as a Dramatic Artist, de Lounsbury, pp. 142-158.
} 
porém contendo um único interlúdio cômico, e - num outro - aqueles nos quais um enredo trágico e um cômico se confluem.

Apesar dos numerosos ataques dirigidos a estes usos em épocas anteriores, e das correspondentes desculpas em nosso tempo, tem havido muito pouco esforço para examinar a prática elisabetana, ou mesmo a de Shakespeare, com vistas a determinar, sem preconceito, até que ponto a junção de cenas trágicas e cômicas foi realmente válida, e o que pode ser pensado para ter significado na arte dos dramaturgos interessados. É objeto de nosso artigo questionar estas questões, e tentar respondê-las, examinando a prática de Shakespeare em relação à dos seus contemporâneos.

Deve ficar claro desde o início que nosso estudo não pode levar em conta, de forma alguma, todos os elementos de engenhosidade e humor que foram introduzidos na tragédia no período estudado. Tentar qualquer censo ou análise dos mesmos, à medida que eles surgirem momentaneamente no diálogo, seria realmente aventureiro. Somente aquelas passagens, consideradas claramente como o resultado da intenção de despertar o riso na audiência, serão consideradas; e tais passagens geralmente envolvem algo do ridículo tanto na ação como no discurso. Quando as cenas deste personagem são devidamente enumeradas nas tragédias dos tempos elisabetanos, elas são vistas como pertencentes à certas classes razoavelmente distinguíveis.

1. Talvez o elemento mais característico, e certamente o mais antigo em desenvolvimento, era o que pode ser chamado de interlúdio do bobo. Podemos facilmente traçar as origens disto em cenas familiares nos mistérios e outras peças populares sérias e antigas, onde o desejo de variedade foi satisfeito pela subação grotesca realizada por personagens de baixa condição social ${ }^{12}$. À medida que a tragédia popular surge no palco elisabetano, cenas destinadas para o bobo - às vezes simplesmente chamado de "bobo", às vezes pelo nome - aparecem: podemos pegar como exemplo típico a cena entre Wagner e o Bobo no Fausto ${ }^{13}$, de Marlowe. Quando estes bobos são identificados como indivíduos com ambiente normal, são geralmente camponeses ou servos de origem rural, mas parece impossível traçar a linha entre o verdadeiro bobo deste personagem e o criado de um tipo mais sofisticado ${ }^{14}$. Para o público londrino do tempo de Shakespeare, a classe servil parece ter se mostrado divertida quase de modo ilimitado; por que é verdade porque, afinal de contas, os empregados domésticos na Inglaterra parecem até hoje oferecer a quem eles servem um pouco mais de divertimento do que na maioria dos outros países familiares- que os sábios expliquem. Fica bastante claro para qualquer leitor do drama elisabetano que, quando os criados aparecem, a comédia

\footnotetext{
12 Os exemplos notáveis, é claro, são Noah e Secunda Pastorum do ciclo de Wakefield. Para a discussão dos elementos cômicos aqui, consulte o ensaio do Professor Gayley intitulado "Representative English Comedies", i, p. xxviii.

${ }_{13}$ Cena IV. A tradução desta peça foi realizada por Bárbara Heliodora, e publicada pela editora Perspectiva na coletânea Dramaturgia Elizabetana, sob o título A Trágica História do Doutor Fausto.

14 Para a conexão do "bobo" com uma classe social definida, compare este verso de uma balada de Robin Hood: "ambos senhor, fazendeiro e bobo" (tradução minha, do original em inglês: "Both gentlemen, yeomen, and clown"). E para a disputada etimologia da palavra, como também uma discussão geral do bobo no palco, consulte o artigo de J. Thümmel, Ueber Shakespeare's Clowns. Shakesp. Jahrb., vol. XI, p. 78.
} 
é realçada, não menos na tragédia do que em outro lugar. Algumas cenas representativas podem ser citadas como exemplos da passagem indefinível do puro interlúdio do bobo, realizado por um personagem reconhecido claramente como "bobo" no interlúdio do servo, onde um certo humor realista de caráter é aproveitado para dar o mesmo tipo de variedade com menos interrupção da ação principal. No ato III, cena V da Tragédia Espanhola15, ocorre uma cena de interlúdio na qual um menino criado soliloquia de forma divertida, enquanto na cena seguinte Pedringano, servo de Bel-Imperia, se entrega a brincadeiras cômicas com o carrasco. Em Arden of Feversham (Ato II, Cena II), Michael, servo de Arden, na abertura da cena carregada com a mais séria importância, entretém seus espectadores com uma cômica carta de amor para sua amante Susan; e novamente, na primeira cena do ato IV, se entrega a palhaçadas e loucuras com seu rival, o pintor. Na Parte II de Tamerlão ${ }^{16}$, um pouco de prosa cômica conclui a primeira cena do Ato IV, onde Calyphas se encontra num diálogo frívolo com seu servo Perdicas. No Fausto, além da cena do bobo já mencionada, temos a cena no pátio da pousada, onde Ralph e Robin se divertem e se envolvem na conjuração de Mefistófeles. No Judeu de Malta ${ }^{17}$, Ithamore, escravo de Barrabás, acrescenta toques cômicos à vilania da ação em muitas cenas do Ato IV, e no último deles, o próprio Barrabás cede a uma parte cômica. Na peça Vingança de Antônio ${ }^{18}$, de Marston, o servo Nutriche fornece duas ou três cenas cômicas estreitamente entrelaçadas com o enredo principal do que o comum. Finalmente podemos perceber o interessante interlúdio de grupos de servos na peça A Woman Killed with Kindness, de Heywood, as quais são praticamente menos bufônicas, em sua pureza, e humanas, de modo bastante realista do que qualquer outra do período, exceto as cenas da Ama em Romeu e Julieta. Em outras palavras, Heywood teve a noção de fazer suas figuras cômicas misturarem com a ação trágica, através de sua leal preocupação com ela ${ }^{19}$.

2. Pode-se distinguir, destas cenas de interlúdio, alguns casos em que um personagem do tipo bobo, ou um tipo substituto, se torna tão importante que reaparece em um número de cenas a intervalos, e formam um tipo de tema

\footnotetext{
${ }^{15}$ Nota do Tradutor: Peça de Thomas Kyd, traduzida por Bárbara Heliodora e compilada na coletânea Dramaturgia Elizabetana, publicada pela Editora Perspectiva.

${ }^{16}$ Outra peça de Christopher Marlowe, também traduzida por Bárbara Heliodora e compilada na Dramaturgia Elizabetana.

${ }^{17}$ Outra peça de Marlowe. Foi encontrada uma tradução em espanhol (El judio de Malta), publicada pela editora Cátedra, de Madrid. A tradução é de Júlio César Santoyo.

18 Sugestão de tradução, embora não tenha encontrado traduções desta peça em outra língua.

19 Percebam especificamente a figura de Jenkin, no Ato II, cena 3, Ato IV, cena III e cena V, ato III. Antes de deixar estes servos bobos, pode ser útil lembrar como M. Maeterlinck experimentou a prática elisabetana, no monótono muito usual de suas tragédias poéticas, em uma cena de Pélleas and Melisande (ato V, cena I). Enquanto a princesa está morrendo, no piso superior, a velha criada está na cozinha discorrendo justamente sobre o humor irrelevante do interlúdio antigo: "Fui eu, sim; fui eu que os encontrei. O porteiro diz que foi êle que os viu primeiro, mas fui que o acordei! Êle dormia, de bôrco, e nao se queria levantar. - - E agora vem dizer : "Fui eu que os vi primeiro". Isso está certo? - Vêde - até me queimei acendendo uma lâmpada para descer à adega. - Mas que tinha eu a fazer na adega? - Não me posso mais lembrar - Enfim, levanto-me às cinco horas; não estava ainda muito claro; disse comigo: vou atravessar o páteo e, depois, abrir a porta. Bem; desço a escada na ponta dos pés, abro a porta, como si fosse uma porta qualquer... Deus meu! Deus meu! Que vejo na minha frente?". (Manuscrito da tradução de Cecília Meireles, digitalizada no Acervo da Biblioteca Nacional).
} 
secundário ou mesmo subenredo para a peça. Desta primeira instância, o exemplo é o anônimo Locrine, onde há o entrelaçamento, com as cenas majestosas da crônica, de uma série de aparições de Strumbo, o sapateiro (cujos companheiros são significativamente chamados "bobos", na lista de dramatis personae); e finalmente, na segunda cena do Ato IV, o tema de Strumbo se funde com o da ação trágica. As aparições cômicas de Mefistófeles no Fausto podem ser consideradas um desenvolvimento do mesmo personagem, assim como as cenas de Ithamore no Judeu de Malta, e um ou dois exemplos já discutidos. As cenas de Snuff em A Tragédia do Ateu ${ }^{20}$ representam uma última aparição de um tipo similar, assim como - com a moda primitiva do bobo por ora deixada de lado - as cenas de Calianax na peça A Tragédia da Donzela ${ }^{21}$. Mas o exemplo mais marcante de uma tragédia na qual as cenas do bobo são de igual importância com as cenas trágicas é $A$ Violação de Lucrécia, de Heywood. Aqui não há apenas um bobo, podemos assim dizer, que aparece em meia dúzia de interlúdios, mas além disso há um cantor engraçado, Valério, cujas canções barulhentas estão relacionadas à história clássica em proporção inversa à sua importância no interesse popular. $\mathrm{O}$ abandono com o qual o dramaturgo permite o clímax da ação, a desonra de Lucrécia, de fato relacionado com uma dessas cantigas cômicas, é talvez o ponto mais baixo da recusa elisabetana de manter a tragédia e a comédia separadas.

3. Outra etapa do desenvolvimento da subação cômica é o aparecimento de um diálogo humorístico ou espirituoso na parte, não por parte dos empregados engraçados ou outros supranumerários, mas dos atores principais, ou pelo menos respeitáveis - aqueles cuja posição social os coloca perto do topo da lista de personalidades. Este tipo de coisa aparece, porém ligeiramente, na tragédia do período shakespeariano, embora Mefistófeles poderia estar classificada aqui, e Tamberlão e Barrabás em uma ou duas ${ }^{22}$ ocasiões $^{23}$. A Tragédia do Ateu, de Tourneur, é talvez a primeira peça a exibir este tipo de diálogo cômico de forma

\footnotetext{
${ }^{20}$ Sugestão de tradução para o título original em inglês: The Atheist's Tragedy, de Cyril Tourneur. Foi encontrada uma tradução em espanhol, porém sem reedição: La tragédia del ateo, traduzida por Bernd Dietz, publicada pela Ediciones Alfaguara.

${ }^{21}$ Original em inglês: The Maid's Tragedy, peça de Francis Beaumont e John Fletcher.

22 Brome, em uma passagem bem conhecida de The Antipodes, na qual a extemporânea fala dos atores bobos é reprovada, sugere que, no período anterior, era compreendido que a brincadeira seria deixada à vontade dos intérpretes:

"Yes, in the dayes of Tarlton and Kempe,

Before the stage was purg'd from barbarism,

And brought to the perfection it now shines with,

Then fooles and jesters spent their wits, because

The poets were wise enough to save their owne

For profitabler uses". Sugestão de tradução deste verso: "Sim, nos dias de Tarlton e Kempe,/ Antes que o palco fosse expurgado da barbárie,/E trazido à perfeição com que agora brilha,/ Os ditos bobos e piadistas gastaram seus espíritos, porque/Os poetas eram sábios o suficiente para salvarem os seus/ Para usos rentáveis".

${ }^{23}$ Nota do Tradutor: Sobre a nota 23: Cabe aqui ressaltar uma observação apontada neste verso por John Payne Coller na obra The Memoirs of the principal actors in the plays of Shakespeare. Segue a tradução da citação de Coller: "Tarlton" claramente é para ser pronunciado em três silabas, e isto será lembrado que é assim escrito no registro de St. Leonard, Shoreditch, onde ele foi enterrado Torrelton". Esta nota de Coller está no capítulo destinado a William Kempe, na página 99, respectivamente. Este verso diz respeito aos atores cômicos William Kempe e Richard Tarlton.
} 
visível, - em conexão, aqui, com o tipo mais engraçado. Beaumont e Fletcher usaram-na eficazmente em A Tragédia da Donzela e em A Vingança de Cupido, começando com uma preferência notável pela espirituosidade sobre o humor, e uma atmosfera de desilusão satírica que é sugestiva - como em muitas de suas obras - das peças misturadas do período da Restauração; este humor bastante inarmônico com o espírito trágico do que o mais amplo humor dos primórdios. Contudo, a mistura de sério e cômico nos personagens e cenas principais é muito mais marcante nas duas grandes tragédias de Webster. Em O Demônio Branco ${ }^{24}$, pode-se dizer que Flamineo encarna em si o espírito desta estranha mistura, que encontra a sua expressão mais ousada no momento em que está perto da morte. "Para onde vou agora? [...] Encontrar Alexandre, o Grande emendando sapatos, Pompeu costurando pontos, Júlio César fazendo prendedores de cabelo com botão [...] Eu peguei um resfriado eterno. Perdi a minha voz de modo irrecuperável"25. Na Duquesa de Malfi² não há um personagem representativo, ainda mais do efeito da mistura, - mistura que nós temos certeza que exprime não meramente uma prática de palco, mas a visão do dramaturgo acerca da vida humana.

4. Um desenvolvimento final da ação cômica na tragédia não é representado estritamente em nenhuma peça do período shakespeariano: a saber, o tipo em que dois enredos de importância aproximadamente igual, um trágico e outro cômico, estão entrelaçados. No final, aparentemente, do período da obra de Shakespeare ${ }^{27}$, esse tipo é exibido em A Condessa Insaciável 28 de Marston. Aqui, um enredo amplamente cômico não apenas se entrelaça com a parte séria da "tragédia", mas, na verdade, substitui a última e controla a cena final. Chegando a este ponto, atingimos o desenvolvimento do interlúdio cômico na verdadeira "tragicomédia".

Sendo estes os tipos de ações cômicas secundárias a serem procuradas na tragédia de nosso tempo, resta saber em que medida elas permeiam essa tragédia. Excluiremos, por enquanto, as tragédias de Shakespeare, a fim de comparar sua prática mais facilmente com a de seus antecessores e contemporâneos. Com exceção de suas peças, o número de tragédias da extensão do tempo de Gorboduc a mais ou menos 1611 ou é perto de cinquenta. Destas, será apropriado excluir para nossos propósitos, peças que seguem distintamente o tipo de crônica histórica, como A Verdadeira Tragédia de Ricardo III e A Tragédia de Thomas Woodstock ${ }^{29}$, exceto em Locrine, onde a inovação do material cômico é encontrada. Em geral, é óbvio, o interlúdio cômico não é uma característica da crônica histórica. Podemos também desconsiderar todo o grupo de tragédias chamadas senecanianas, incluindo, além

\footnotetext{
${ }^{24}$ Original em inglês: The White Devil. Foi encontrada uma tradução em espanhol: El Diablo Blanco, traduzida por Fernando Villaverde e publicada pela Editora Nacional, de Madrid.

${ }^{25}$ Sugestão de tradução para os versos em inglês: "Whither shall I go now? [...] To find Alexander the Great cobbling shoes, Pompey tagging points, and Julius Caesar making hair buttons!" [...] I have caught an everlasting cold. I have lost my voice most irrecoverably"

${ }^{26}$ Original em inglês: The Duchess of Malfy. Foi encontrada uma tradução em espanhol: La Duquesa de Amalfi, traduzida por Jorge Salavert.

27 Schelling coloca a data da composição como 1610-1613.

28 Original em inglês: The Insatiate Countess.

${ }^{29}$ Original em inglês: The Tragedy of Thomas Woodstock.
} 
de Gorboduc, Jocasta ${ }^{30}$, As Desgraças de Arthur 31 , e seus semelhantes, os dramas de Daniel, Fulke Greville e Sir William Alexander, e as traduções de Garnier; pois nestes dramas senecanianos e dramas literários ${ }^{32}$ não se imaginava o interlúdio ou a ação secundária cômicos. Feito isto, permanecem trinta tragédias das cinquenta elencadas; e estas, com sorte, podem ser divididas em três grupos de tamanhos não diferentes. O primeiro é composto de peças que praticamente não têm cenas cômicas; inclui David and Bethsabe e A Batalha de Alcazar, de Peele; a peça anônima A Warning For Fair Women; Sophonisba, de Marston, Sejanus e Catiline, de Jonson; Revenge of Bussy ${ }^{33}$ e Tragedy of Biron ${ }^{34}$, de Chapman; e The Devil's Charter 35 , de Barnes. (A maioria destas tragédias, como se notará, datam de um tempo após 1600). O segundo grupo é formado de peças nas quais o material cômico aparece em poucas cenas isoladas - às vezes em uma, às vezes em três ou quatro, - variando de um diálogo cômico momentâneo à uma sucessão de interlúdios como os já citados em A Woman Killed with Kindness. As tragédias deste tipo são: A Tragédia Espanhola, de Kyd (Ato III, Cenas V e VI) ${ }^{36}$; Arden of Feversham (Ato II, Cena II, Ato IV, Cenas I e II); Tamberlão, Parte 2 (Ato III, Cena V; Ato IV, Cena I); O Judeu de Malta (Ato IV, Cenas II, III, IV e VI), Lust's Dominion (Ato III, Cena V, Ato IV, Cena V); o Bussy D'Ambois, de Chapman (Ato I, Cena II), A Woman Killed With Kindness, de Heywood (Ato I, Cena II, Ato II, Cena III, Ato IV, Cena III, Ato V, Cena III), A Tragédia do Vingador37, de Tourneur (Ato II, Cena I38), Cupid's Revenge, de Beaumont e Fletcher (Ato I, Cena I, Ato II, Cena I, Ato III, Cena I, Ato IV, Cena I (?)). O terceiro grupo consiste de peças nas quais os elementos cômicos são introduzidos repetidamente, ou em uma extensão suficiente para sugerir um tipo misto de drama, a saber: Locrine (Ato I, Cena II, Ato II, Cenas II e III, Ato III, Cena III, Ato IV, Cena II); Soliman and Perseda, de Kyd (Ato I, Cenas III e IV, Ato II, Cena II, Ato III, Cena II, Ato IV, Cena II, Ato V, Cena III); Fausto, de Marlowe (Cenas IV, VII, VIII, IX e XI), Antonio's Revenge, de Marston (Ato I, Cena II, Ato II, Cena I, Ato III, Cena II, Ato IV, Cena I, Ato V, Cena I), Hoffman, de Chettle (Atos I, II, III, passim),

\footnotetext{
30 Peça de Sêneca.

31 Original em inglês: The Misfortunes of Arthur. Peça de Thomas Hughes.

32 Original em inglês: closet dramas.

${ }^{33}$ Nota do Tradutor: É possível encontrar a peça com o título The Revenge of Bussy D'Ambois.

${ }^{34}$ Nota do Tradutor: É possível encontrar a peça com o título The Conspiracy and Tragedy of Charles, Duke of Byron.

35 Em A Warning For Fair Women, há duas cenas onde os personagens humildes do gênero são introduzidos, com efeitos cômicos momentâneos se os atores escolheram se aproveitar da oportunidade, - as cenas de Barnes e Beane, e de John e Joan (na obra School of Shakespeare, de Simpson, vol II, pp 275, 291). A mesma questão pode ser levantada a respeito de The Devil's Charter, onde os malfeitores Frescobaldi e Baglioni (Ato III, Cena II e Ato V, Cena I) apresentam um humor sombrio que pode ou não ter sido enfatizado no palco.

36 Por conveniência de referência, observo aproximadamente as cenas enumeradas para esta classificação. Obviamente, nenhum leitor seria capaz de concordar em todos os detalhes de tal escolha, e eu não posso esperar ter evitado passar por cima de algumas cenas que podem merecer menção tanto quanto as indicadas.

${ }^{37}$ Original em inglês: The Revenger's Tragedy. Foi encontrada uma tradução em espanhol, La tragédia del vingador, publicada em 1987 pela Alfaguara Ediciones. A tradução é de Bernd Dietz. Não foram encontradas reimpressões.

38 Além do diálogo cômico desta cena, pode-se notar o humor amargo de Vendice, passim.
} 
The Rape of Lucrece39, de Heywood (passim), A Tragédia do Ateu, de Tourneur (Ato I, Cena III, Ato II, Cenas I e VI, Ato IV, Cenas I, III, IV e V, Ato V, Cena I), A Tragédia da Donzela, de Beaumont e Fletcher (Ato I, Cena II, Ato II, Cena I, Ato III, Cenas I e II, Ato IV, Cena II, Ato V, Cena II), A Condessa Insaciável, de Marston (Ato I, Cena I, Ato II, Cena I, Ato III, Cenas I e III, Ato IV, Cena IV, Ato V, Cena II), O Demônio Branco, de Webster (Ato I, Cena II, Ato II, Cena I, Ato III, Cena I, Ato V, Cenas I, III, IV e VI), A Duquesa de Malfi (Ato I, Cena, I, Ato II, Cenas I e II, Ato III, Cenas II e III, Ato IV, Cena II ${ }^{40}$, Ato V, Cena II).

Com a análise da prática de seus contemporâneos em mente, voltemos às tragédias de Shakespeare. Em Romeu e Julieta, talvez a sua primeira tragédia, aparece uma grande quantidade de material cômico. A peça abre com uma cena de servos fanfarrões, enquanto os empregados domésticos convencionais fornecem breve interlúdio cômico na abertura de Ato I, Cena V, e no Ato IV, Cena II. Além disso, há um criado chamado "Bobo41", que fornece um típico interlúdio de clown no Ato I, Cena II ("a mim mandam encontrar a gente que tem o nome escrito aqui, quando eu não sei descobrir que nomes a pessoa escrevinhadora escreveu aqui ${ }^{42}$ "), e outro criado, chamado Pedro, o qual faz uma aparência presumivelmente cômica por breves momentos no Ato II, Cenas IV e V, e apresenta uma cena importante de interlúdio na conclusão do Ato $\mathrm{IV}^{43}$. Além da riqueza da ação secundária do personagem bobo antiquado, nós temos a personagem da Ama, uma personagem do gênero que proporciona a comédia de costumes na conexão imediata com a ação (veja especialmente o Ato I, Cena III, Ato II, Cenas IV e V44). E finalmente, no personagem de Mercúcio, o dramaturgo introduz um diálogo cômico do tipo mais gentil, por parte de uma das personagens que é socialmente, senão dramaticamente, importante. Poder-se-ia quase conceber Shakespeare decidindo, nesta sua primeira tragédia original, superar seus contemporâneos no uso livre e eficaz de todo tipo de contraste e mistura que os diferentes tipos de material cômico tornaram possíveis. Mas considerações mais próximas trazem à luz o fato de que o uso deste material em Romeu e Julieta pode ser distinguido por uma circunstância importante de praticamente todas as tragédias que analisamos. É o fato de que ação secundária cômica é amplamente reunida no início da peça, diminuindo já no terceiro ato, e sendo inteiramente insuficiente no último. Mercúcio morreu, com

\footnotetext{
${ }^{39}$ Embora exista um poema de Shakespeare com o mesmo título, não foram encontradas traduções do referido texto de Heywood. As possíveis traduções do poema shakespeariano são: Violação de Lucrécia, Estupro de Lucrécia, Profanação de Lucrécia.

40 Esta é a cena dos loucos, e representa um tipo diferente de efeito cômico de qualquer um que tenha sido discutido; diferente, também, de qualquer outro período, mas análogo à cena de Ofélia em Hamlet (Ato IV, Cena V). Nesse caso, o riso e a dor não são tão contrastados quanto despertados simultaneamente (ver o livro de John Corbin: The Elizabethan Hamlet).

${ }^{41} \mathrm{Na}$ tradução usada, Clown foi traduzido por "Criado".

${ }^{42}$ Trecho original em inglês: "I am sent to find those persons whose names are here writ, and can never find what names the writing person hath here writ")

${ }^{43}$ Este interlúdio é distinto de todos os outros em não ter nenhuma conexão com a ação para servir como raison d'etre, e sendo, portanto, obviamente feito ad hoc. É ainda mais interessante o fato de que a direção do palco no Q2 dá evidência de que a peça foi interpretada por Will Kemp, um comediante líder do período. Sobre ele, mais informações a seguir.

44 No artigo de Thümmel mencionado anteriormente, a Ama é tratada como um bobo; porém, outras questões, que não o seu sexo, tornam isso duvidoso.
} 
uma piada nos lábios, na primeira cena do Ato III; as outras aparições da Ama perdem sua exuberância cômica; e se não fosse pelos interlúdios destes dois servos que contornam a aparente morte de Julieta no Ato IV, Cena V (onde talvez possamos supor que é necessário sermos obrigados a deixar de lado um clima trágico até que as verdadeiras aflições por vir tenham amadurecido), toda a segunda metade da peça seria quase puramente séria. Este mergulho da abundante alegria das primeiras cenas para a depressão rapidamente aprofundando das últimas, produz um efeito muito característico; pode-se chamá-lo comi-tragédia.

Basta dizer que não há outra tragédia de Shakespeare como Romeu e Julieta no que diz respeito ao caráter ou ao arranjo dos detalhes cômicos. Por algum tempo depois, ele parece não ter escrito mais tragédias, e quando voltou à forma, acabou tratando, em geral, com seriedade penetrante. O interlúdio cômico, no entanto, não foi de modo algum abandonado. Ele reaparece sob diversas formas, peculiarmente como uma única interrupção da ação principal, por um personagem bufão que não aparece em outra parte. Em Hamlet, enquanto há uma abundância de matéria cômica (para certos aspectos de que devemos retornar mais tarde), uma única cena de clown aparece no último ato, os coveiros sendo nomeados "clowns" no texto. Em Othello, o bobo também é explicitamente marcado: ele aparece na abertura do Ato III, fazendo piadas com os músicos muito à moda de Pedro em Romeu e Julieta ${ }^{45}$. Em Macbeth, o bobo é o humorístico Porteiro (Ato II, Cena III), cujas piadas suspendem a ação em um momento tão crítico ${ }^{46}$. Em Antônio e Cleópatra, ele é chamado novamente de "bobo", mas agora ele tem uma função de importância, como o camponês que traz para Cleópatra o "verme do Nilo47" (Ato V, Cena II) um dos mais envolventes desses humoristas menores. Em Coriolano, não se pode encontrar um interlúdio puramente cômico, mas temos a relíquia, por assim dizer, sob o temperamento atual do dramaturgo, na cena dos servos antiquados no Ato IV, Cena V ${ }^{48}$. Desta lista, três tragédias foram omitidas: Júlio Cesar, Rei Lear e Tímon de Athenas. Na última, um bobo toma o lugar do bufão, aparecendo na cena habitual do interlúdio no Ato II, Cena II. Em Lear, onde a mesma inovação é praticada, a importância do bobo exige que ele seja reservado para discussão separada. Em Júlio César, há bufões na própria abertura da peça nas pessoas do Carpinteiro e o Sapateiro, um companheiro espirituoso em respostas, foi pensado como o bufão da peça. Se procurarmos uma cena de interlúdio, não obstante, a

\footnotetext{
${ }^{45}$ Ele não tem nenhuma parte a desempenhar na ação, e o professor Bradley o considera um bobo "pobre", acrescentando: "nós dificilmente presenciamos ele e rapidamente o esquecemos. Eu acredito que a maioria de leitores de Shakespeare, se forem perguntados se há um bobo em Otelo, responderiam Não". (Shakespearean Tragedy, p. 177. Citação original: "we hardly attend to him and quickly forget him; I believe most readers of Shakespeare, if asked whether there is a clown in Othello, would answer no".

${ }^{46}$ Nesta cena, vemos os vários comentários citados no New Variorum, pp. 144-146, particularmente as importantes observações de Hales (de seu Notes and Essays); e Bradley, pp. 395-397. As observações de Bradley servem para explicar por que em uma passagem anterior (p. 311) ele havia dito, com efeito, que não há interlúdio do bobo em Macbeth. Contudo, como ele admite que os espectadores provavelmente "estrondaram gargalhadas" nas observações do Porteiro, a afirmação não pode ser justificada.

${ }^{47}$ Original em inglês: "worm of Nilus". A tradução usada desta passagem foi a de Carlos Alberto Nunes (1958).

48 Para outras cenas parcialmente cômicas em Coriolano, ver infra.
} 
encontraremos no Ato IV, Cena III, onde o poeta cínico interrompe os generais. No mero texto, a comédia desta passagem é suficientemente pequena, mas se nos lembrarmos de que Shakespeare havia encontrado o poeta mau descrito em Plutarco como alguém que "pusera a imitar a filosofia [...] com uma impetuosa e furiosa paixão ${ }^{49}$ " que fez Cássio "se pôr a rir ${ }^{50 "}$, pode não parecer impossível que ele foi tratado no palco com alguma bufonaria do interlúdio cômico ${ }^{51}$.

O significado de tudo isso reside no fato, que aparentemente nunca foi observado, de que Shakespeare fez uma prática, no período principal de sua obra dramática, de evitar os interlúdios cômicos repetidos de muitos de seus predecessores e contemporâneos, introduzindo, mesmo assim, uma única cena do bobo como uma concessão à tradição popular - e talvez às exigências de sua companhia, onde ao seu comediante principal deveria ser fornecido uma parte ${ }^{52}$. Às vezes esta cena do bobo era completamente diferente da ação na peça, como em Romeu e Julieta e Otelo, e Shakespeare, com muita frequência, preferiu entrelaçá-la efetivamente com o material da tragédia, como notavelmente em Hamlet e Antônio e Cleópatra. Macbeth pôde formar um tipo intermediário: a cena do porteiro poderia ser removida sem afetar a ação, apesar da objeção de Coleridge, que poucos críticos a chamariam de gratuita.

${ }^{49}$ Original em inglês: "took upon him to counterfeit a philosopher [...] with a certain bedlam and frantic motion". A tradução usada foi a consultada no portal Consciencia.org. Não consta o nome do tradutor, nem data de publicação.

50 Original em inglês: "a-laughing". A tradução usada também é a do portal Consciencia.

51 Titus Andronicus foi ignorada por razões óbvias. Se incluída, no entanto, ela se encaixa precisamente com a prática vigente de Shakespeare: há um único interlúdio do bobo no Ato IV, Cena III ("Entra o bobo, com um cesto", etc.)

52 A este respeito, o nome de Will Kemp é lembrado, já que ele é conhecido por ter interpretado o papel de Pedro em Romeu e Julieta, e por ter sido, durante períodos consideráveis, o principal bobo da companhia de Shakespeare. A ele também foi conjenturalmente atribuída a parte do primeiro coveiro em Hamlet (primeiro, talvez, por Chalmers). Collier, por outro lado, uma vez que Kemp parece ter agido em 1602 com outra empresa, acreditava que Shakespeare estava lançando uma injúria sobre ele nas linhas, "Deixe aqueles que interpretam seus bobos não falem mais do que está designado para eles", etc. (Memoirs of the Principal Actors, etc, p. 89. Citação original: "Let those that play your clowns speak no more than is set down for them". E veja, para mesmo efeito, Brinsley Nicholson em "Kemp and Hamlet, Transaction N. S. S., 1880, p. 57). Se ele fosse o William Kemp, cujo registro de enterro Chalmers encontrou sob a data de 2 de novembro de 1603, não podemos supor que ele parecia interromper o curso sério de qualquer das tragédias subsequentes a Hamlet, mas se ele sobreviveu esse ano, como é bastante possível, ele pode ter interpretado o bobo em Othello e o porteiro em Macbeth. Olhando para trás novamente, é quase certo que ele estava na companhia de Shakespeare quando Júlio César foi produzida, pois ele é conhecido por ter interpretado Dogberry naquela época em Muito Barulho por Nada. Ele pôde, então, ter interpretado o sapateiro, ou o mau poeta da cena da tenda - se, como foi sugerido, aquela cena era mais cômica do que o texto revela, ou ambos. Tudo isso é conjetura ociosa, mas o fato de que uma personagem como Kemp era uma peça importante da companhia teatral, e que para ele e seus interlúdios em tragédias foram deliberadamente feitos (como parece ter sido o caso com a cena de Pedro em Romeu e Julieta), está muito longe do que é fundamental para o estudo do nosso assunto. (Para as contas de Kemp, além do artigo parcialmente pouco confiável de Collier, veja a edição de Dyce da obra de Kemp Nine Days Wonder, Camden Society, 1840, um artigo sem autoria no Jahrbuch, XXII, p. 255, e, claro, o Dictionary of National Biography). Nota do Tradutor: Embora o artigo original cita a edição de 1840 da peça de Kemp, foi possível encontrar a edição digitalizada de 1839, a qual se encontra nas referências finais desta tradução. 
Rei Lear apresenta um caso por si só. Aqui Shakespeare não só, como se observou, variou da prática comum ao trazer um bobo da corte para a tragédia, como na verdade, o tornou um dos personagens importantes da peça. Ele prova, naturalmente, que não é inteiramente um personagem cômico: na sua primeira aparição (Ato I, Cena IV), ele é chamado de "bobo amargo", logo é evidente que ele está emocionalmente preocupado com o destino do rei, e sua posição no segundo e no terceiro atos (Ato II, Cena IV, Ato III, Cenas II, V e VI) torna-se cada vez mais de um trágico sofredor, embora devamos, sem dúvida, supor que suas investidas propunham diversão também. Após o Ato III, ele desaparece. Este bobo tem sido objeto de nenhuma interpretação crítica, e não é para o presente propósito tentar mais ${ }^{53}$. Mas é pertinente observar que temos aqui o exemplo supremo da transfiguração do antigo interlúdio cômico e sua mistura completa com a ação séria - não só a ação, mas o caráter emocional - da tragédia. O resultado é um complexo emocional extraordinário, que é parcialmente expresso pelo termo trágico pathos, mas que é muito intrincado, para não dizer caótico, para análise. É o ápice da arte "gótica".

O material cômico nas tragédias não está, é claro, inteiramente coberto pelas cenas cômicas de interlúdio que foram enumeradas. Além destas, em primeiro lugar, há os flashes momentâneos de espirituosidade ou humor que configuram sobre o diálogo, e não podem, como já foi dito, serem listados para qualquer propósito como o nosso. Novamente, há certos momentos de ação cômica, evidentemente concebidos para suscitar risadas gerais, porém distintos das cenas de interlúdio no quesito brevidade ou sua conexão mais próxima com a ação trágica principal: a embriaguez de Cássio em Otelo (Ato II, Cena III), o engano de Rodrigo na mesma peça (fim do Ato II e Ato IV, Cena II ${ }^{54}$ ), a embriaguez de Lépido em Antônio e Cleópatra (Ato II, Cena VII), o diálogo dos atendentes de Cleópatra na mesma peça (Ato I, Cena II), o humor sombrio da população em Júlio César (Ato III, Cena III), e Coriolano (Ato II, Cena III), a grosseira conversa dos vigias na última peça (Ato V, Cena II), o ato infantil do pequeno filho de Lady Macduff em Macbeth (Ato IV, Cena II) e o único discurso - uma vez mais humorístico e mais

\footnotetext{
${ }^{53}$ Eu não consigo resistir em citar o bom comentário de Professor Bradley: "Pode-se quase imaginar que Shakespeare, voltando de uma noite no Mermaid, onde tinha ouvido Jonson fulminando contra os bobos em geral e talvez criticando o bufão em particular em Noite de Reis, disse a si mesmo: "Venham, meus amigos, eu mostrar-vos-ei de uma vez por todas que o mal está em vós, e não no bobo ou na audiência. Tenho um bobo na mais trágica das minhas tragédias. Ele não deve desempenhar um pequeno papel. [...] Ao invés de entreter as horas ociosas do rei, ele estará ao seu lado na mesma tempestade e turbilhão da paixão. Antes de fazê-lo, vós o confessarás, entre risos e lágrimas, que ele é da própria essência da vida" (Shakespearean Tragedy, p. 311. Citação original: "One can almost imagine that Shakespeare, going home from an evening at the bar, where he had listened to Jonson fulminating against fools in general and perhaps criticising the clown in Twelfth Night in particular, had said to himself: "Come, my friends, I will show you once for all that the mischief is in you, and not in the fool or the audience. I will have a fool in the most tragic of my tragedies. He shall not play a little part. [...] Instead of amusing the king's idle hours, he shall stand by him in the very tempest and whirlwind of passion. Before I have done you shall confess, between laughter and tears, that he is of the very essence of life").

54 A descrição de Rodrigo entre os dramatis personae como "fidalgo trouxa" marca sua função intencionalmente cômica.
} 
patético - do pequeno Márcio em Coriolano (Ato V, Cena III) - estas quase, mas sem dúvida não totalmente, esgotam a lista 55 .

Para resumir o que descobrimos: das tragédias de Shakespeare, a primeira contém dez ou doze cenas parcialmente cômicas, em outras há de vinte a vinte e cinco - claro que não haveriam dois leitores que concordassem na contagem - uma média de um pouco menos de três em cada peça. Destas cenas, uma em cada tragédia, exceto Lear, participa da natureza do antigo interlúdio do bobo: em Lear, o bufão, agora convertido em bobo, é transformado para um personagem importante e parcialmente sério. As outras cenas cômicas são de vários tipos. Três tragédias, Júlio César, Otelo e Macbeth, estão livres de detalhes cômicos marcantes, exceto para a única cena de interlúdio ${ }^{56}$, embora mostrando momentos secundários de uma ação secundária divertida. Duas tragédias têm cenas cômicas no primeiro ato, sete cenas no segundo, três cenas no terceiro, quatro cenas no quarto e três cenas no quinto ${ }^{57}$. Não há nenhuma peça, na qual o material cômico tende a subir para a posição de um subenredo, nem qualquer, na verdade, que possa ser pensado para dar garantia à afirmação de Dr. Johnson, onde na tragédia Shakespeare "está sempre lutando depois de alguma ocasião para ser cômico".

No sumário anterior, apenas a cena do cemitério em Hamlet foi incluída. No entanto, é claro que uma porção considerável de Hamlet, não facilmente inserida em qualquer um dos grupos até agora observados, ainda está marcada por efeitos cômicos distintos. Tão longe de ser da natureza do interlúdio, esse elemento está envolto na personalidade do próprio Hamlet, e nos lembramos que, nessa peça, temos o único exemplo de uma tragédia shakespeariana cujo herói é, em certa medida, uma parte cômica ${ }^{58}$. Nos diálogos de Hamlet com aqueles que ele

\footnotetext{
${ }^{55}$ Exceto por Timon, cujo caráter satírico torna muito difícil distinguir o que é cômico do que é sério. Por exemplo, a cena da festa da água quente (Ato III, cena VI) - é comédia ou tragédia? Nem, podese dizer, ou ambos. O humor satírico também aparece em Coriolano, e mesmo em Antônio e Cleópatra, diminuindo grandemente o efeito trágico total (novamente o termo comi-tragédia pode ser usado), e tornando possível para o professor Bradley falar de Macbeth como "a última das puras tragédias". Aqui também deve ser mencionado Troilus e Cressida, que é talvez tão trágico quanto Timon. Essa peça, lembra-se, os editores do Folio aparentemente não sabiam classificar: é como um drama moderno e familiar no qual o fim é uma dissonância, sem resolução cômica nem trágica. O fim da ação é a morte de Hector, mas a última palavra (provavelmente não a de Shakespeare, para ter certeza) é uma risada zombadora.

${ }^{56}$ Esta declaração, creio eu, seria aceita pela maioria dos leitores de Otelo, mas desde que foi escrito, eu vi Otelo bem performado, e foi atingido não só pelo "alívio" cômico fornecido por Rodrigo, o personagem trouxa, mas também pela diversão que a audiência encontrou nos gracejos espirituosos de Iago, apesar da terrível importância daquilo que eles estavam levando.

57 Romeu e Julieta ainda estão excluídos desses números. O Professor Bradley observa, de modo justo, que as passagens cômicas ocorrem "com maior frequência no início ou no meio da peça", enfatizando seu uso no quarto - ou no início do quinto - ato como um meio de prevenir o "impedimento" que ameaça a tragédia do ato quinto a este ponto. (Shakespearean Tragedy, página 61). Isso sugere um aspecto do nosso assunto que não é abordado neste artigo, ou seja, a relação da subcena cômica à técnica dramática. Um exemplo interessante é a observação, feita em primeiro lugar, que não posso agora dizer por quem, que a cena de porteiro em Macbeth foi planejada para dar tempo a Macbeth lavar as mãos e trocar de roupa.

58 Compare a observação de Furnivall de que "o próprio Hamlet faz o trabalho principal do bobo de Lear". (Transactions, N. S. S., 1880, p. 65. Citação original: "Hamlet himself does the main work of Lear's fool".
} 
despreza - com Polônio, Rosencrantz e Guildenstern, e Osric -, está uma das mais brilhantes comédias intelectuais em Shakespeare. Explicar ou interpretar a presença desta matéria na maior das tragédias, não é nossa tentativa aqui. Basta observar que tende a fazer do drama o que poderia ser chamado de complexo intelectual, em comparação com o que se chamava de complexo emocional no caso do Rei Lear, e que o efeito dominante agora é o da trágica ironia comparada com a impressão de trágico pathos.

Também não podemos deixar de notar a parte interessante representada pela insanidade, real ou fingida, na criação desses complexos. Esse distúrbio mental foi uma fonte reconhecida de diversão no período elisabetano, onde tem sido abundantemente performada ${ }^{59}$, mas isso não é negar que isso nunca possa ter falhas em seu poder de despertar a piedade e o terror. Se o Professor Wendel e o Sr. Corbin estão certos em suas ênfases no lado cômico deste elemento em Lear e Hamlet ser questionado, e não podemos discutir aqui, mas é certo que, exceto para leitores que rejeitam completamente a possibilidade de tal dissonância do humor e pathos, a presença de material cômico nas cenas loucas, como naquelas que Webster ${ }^{60}$ provavelmente extraiu, devem ser vistas como importantes para uma compreensão completa do nosso tema. Em Rei Lear, o assunto é de importância única, devido à extraordinária combinação da loucura real do rei, da loucura parcial do bobo e da loucura fingida de Edgar. Os leitores, assim dispostos, podem muito bem perguntar quais destas cenas são principalmente instrumentais em efetuar o que foi chamado de trágica ironia, e qual de trágico pathos. Certamente, na loucura fingida de Hamlet, o primeiro é notável, e o último na verdadeira loucura de Lear. $\mathrm{O}$ público pode rir em ambos os $\operatorname{casos}^{61}$, mas a diferença pode ser expressa de alguma forma: para rir em Hamlet é necessário entender, enquanto para rir em Lear não é necessário.

Esta última fase de nosso assunto sugere uma investigação conclusiva, que está aqui para ser levantada ao invés de respondida. Quão verdadeira é a afirmação comumente feita, que a presença de detalhes cômicos na tragédia é para o propósito de alívio? Alívio, no sentido literal do contraste - sobre isso, pode haver

\footnotetext{
${ }^{59}$ Consulte as obras William Shakespeare, de Wendel e The Elizabethan Hamlet, de Corbin.

${ }^{60}$ Veja a nota sobre A Duquesa de Malfi, supra (Nota 41), e John Webster, de Stoll, p. 142-144.

${ }^{61}$ Um público moderno não é tanto, certamente, um elisabetano, mas às vezes, como qualquer observador pode descobrir. O professor George P. Baker parece questionar isso, pelo menos no que se refere a Hamlet, em sua recente introdução à essa peça no Tudor Shakespeare, dizendo que se "Shakespeare pretendia tornar cômica a loucura fingida, [...] depois em cenas profundamente comoventes e ricas na melhor psicologia que ele trabalhou para um riso, deve, em grande parte, romper o feitiço muito emocional que parece estar tentando criar" (p. XV-XVI. Original em inglês: "Shakespeare meant the pretended madness to be comic, [...] then in scenes profoundly moving and rich in the finest psychology he worked for a laughter that must largely break the very emotional spell he seems to be seeking to create"). Mas isso é para fugir da questão central - onde não há um "feitiço emocional", onde elementos sérios e cômicos contribuem. A sugestão do professor Bradley, neste caso, em relação à cena do porteiro em Macbeth, é que a ideia de Shakespeare era que os espectadores berrariam de tanto gargalhar e, ao mesmo tempo, "desprezava-os se riam". Isto pode parecer um calvinismo muito supralapsariano, para representar o poeta criando os pecadores para depois condená-los, mas quando consideramos o problema da relação dos poderes majestosos de idealização de Shakespeare com seus parceiros como fornecedor de drama ao povoado, sem dúvida, isso contém um aspecto de verdade.
} 
pouca dúvida ${ }^{62}$. A respeito da visão predominante de que a função principal de tais cenas é relaxar a tensão da carga trágica63, pode-se levantar alguma questão. $\mathrm{O}$ exemplo padrão para esse ponto de vista é a cena do porteiro em Macbeth, mas uma testemunha tão importante como o professor Bradley nos diz que isso não o faz sorrir ${ }^{64}$. Em geral, descobrimos que, na prática de Shakespeare, as cenas de interlúdio são mais usadas nas tragédias que menos se movem para o horror e o desespero. Em Otelo, onde a necessidade de "alívio" é talvez maior, essas interrupções são comparativamente poucas. Em Lear, os detalhes quase cômicos são bastante abundantes como vimos, mas devem ser considerados como intensificadores das emoções trágicas ao invés de suavizá-las. O mesmo acontece com o material cômico mais ousado em Hamlet. Há matéria aqui para análise cautelosa, que a psicologia pode, com tempo, realizar para nós ${ }^{65}$. Entretanto, podese suspeitar, em vista do que vimos, que o aspecto mais significativo do uso do cômico na tragédia não é o que se deve essencialmente ao apego à variedade e ao contraste (importante como é o caso dos mais primitivos tipos), mas sim àquele que busca personificar um estado mental ou emocional mais complexo e mais dramaticamente em movimento do que os estados mais puros e mais simples, aos

62 Compare a defesa de Dryden sobre a prática, na personagem de Neandro: "por que ele deve imaginar a alma de um homem pesar mais que seus sentidos? $O$ olho não passa de um objeto desagradável para um agradável em um tempo muito mais curto do que é necessário para isto? "E o desagradável dos primeiros não elogiam a beleza do último? A velha regra da lógica poderia convencê-lo, que os contrários, quando colocados perto, se explodem". (A tradução é minha do original em inglês: "why should he imagine the soul of a man more heavy than his senses? Does not eye pass from an unpleasant object to a pleasant in a much shorter time than is required to this? And does not the unpleasantness of the first commend the beauty of the latter? The old rule of logic might have convinced him, that contraries, when placed near, set off each other". (Essays, ed. Ker, I, p. 70).

${ }^{63}$ Cf. Thümmel, por exemplo: "Quanto mais aguda e tormentosa se aguça o curso pragmático na tragédia, mais impreterivelmente necessária impõe-se ao espectador a necessidade de suavização da situação penosa. Tal atenuação pode ser, pelo menos, e é, mais certamente, alcançada por meio de uma cena episódica de tom cômico". (Original em alemão: "Je schärfer und beängstigender der pragmatischer Verlauf im Trauerspiel sich zuspitzt, um so unabweislicher stellt sich beim Zuschauer das Bedürfniss nach Milderung der peinlichen Situation ein. Diese Milderung kann immerhin und wird am sichersten durch eine episodische Scene komischer Farbung her-beigeführt werden" (Jahrbuch, vol. XI, p. 83). Agradeço ao professor Stéfano Paschoal (UFU), Doutor em Língua e Literatura Alemã pela USP, por ajudar na revisão da tradução, impedindo o tradutor de um grande deslize.

64 "O momento é fantástico... [As observações do porteiro] não são suficientemente cômicas para permitir que se esqueça por um momento o que precedeu e o que deve se suceder" (Shakespearean Tragedy, p. 395, tradução do original em inglês: "The moment is too terrific... [The porter's remarks] are not comic enough to allow one to forget for a moment what has preceded and what must follow".

${ }^{65}$ Volkelt, em seu admirável AEsthetitk des Tragischen, não sente que ele pode entrar no assunto, exceto pela observação sugestiva de que "Poesias como o Lear de Shakespeare [...] mostram que cenas cômicas não apenas podem ser reunidas com o trágico, como é evidente nos mistérios medievais, mas também que, entre o humor e o trágico há uma relação de pertença intrínseca, plena de sentido e profunda" (Citação original em alemão: "Dichtungen wie Shakespeare's Lear [...] bezeugen dass komische Szenen mit dem Tragischen nicht nur, wie in den mittelälterlichen Mysterien äusserlich zusammengestellt werden können, sondern dass zwischen dem Humor und dem Tragischen innere Zusammengehorigkeit sinnvolle und tiefgehende Bezogenheit stattfindet" (Page 393). Mais uma vez agradeço ao professor Stéfano por impedir outro deslize do tradutor. 
quais o drama da escola clássica geralmente se confina. Lessing, ao atacar o "drama comi-trágico ou tragicômico [...] da invenção "gótica"”, sustentou que não é defesa alguma afirmar que isso imita a variedade da natureza, porque, disse ele, enquanto pode imitar a natureza dos fenômenos, ignora a natureza das emoções, a qual é função da arte nos ajudar a unificar ${ }^{66}$. A resposta parece ser que - de qualquer modo nos espécimes mais altos do método "gótico" - o objeto não é para retratar a confusão da natureza exterior como a confusão da alma nos momentos em que trágico e cômico parecem formar uma experiência indivisível.

\section{Referências}

\section{Referência Principal}

ALDEN, Raymond Macdonald. The Use of Comic Material in the Tragedy of Shakespeare and His Contemporaries. The Journal of English and Germanic Philology, Illinois, vol. 13, nº. 2, 1914, p. 281-298.

\section{Referências Complementares}

ADDISON. N. 40 - Monday, April 16, 1711. In: MORLEY, Henry (ed). The Spectator: A New Edition Reproducing the Original Text Both as First Issued and as Corrected by its Author. Volume 1. London: George Routledge and Sons, 1891.

BAKER, George Pierce. Hamlet Prince of Denmark: The Tudor Shakespeare. USA: MacMillan, 1913.

BRADLEY, Andrew Cecil. Shakespearean Tragedy: Lectures on Hamlet, Othello, King Lear, Macbeth. 1. ed. Glasgow: Glasgow University Press, 1904.

COLLIER, John Payne. Memoirs of the principal actors in the plays of Shakespeare. London: Shakespeare Society, 1846.

CORBIN, John. The Elizabethan Hamlet: a study of the sources and of Shakespeare's environment, to show that the mad scenes had a comic aspect now ignored. London: London E. Mathews, 1895.

\footnotetext{
66 Dramaturgie, LXX. "Tudo o que segregamos ou que desejamos poder segregar em nosso pensamento, no que diz respeito a um objeto ou a uma relação entre diferentes objetos, seja do tempo ou do espaço - segrega realmente a arte, e acede-nos este objeto ou esta relação de objetos diferentes de modo tal mais conciso, como se apenas isso permitisse a sensação que eles (objeto e relações) deveriam despertar. Deve, necessariamente, causar-nos repugnância, encontrar novamente na arte aquilo que gostaríamos de ver banido da natureza". Tradução do original em alemão: "Alles, was wir in der Natur von einem Gegenstande oder einer Verbindung verschiedener Gegenstande, es sei der Zelt oder der Raume nach, in unsern Gedanken absondern oder absondern zu können wünschen, sondert sie [die Kunst] wirklich ab, und gewährt uns diesen Gegenstand oder diese Verbindung verschiedener Gegenstände so lauter und bündig, als es nur immer die Empfindung, die sie erregen sollen, verstattet [...] Es muss uns notwendig ekeln, in der Kunst das wiederzufinden, was wir aus der Natur wegwünschten".
} 
DRYDEN, John. Dedication to Spanish Friar, or the double discovery (1681). In: KER, Willian Paton (ed). Essays of John Dryden. Vol. 1. Oxford: Clarendon Press, 1906, p. 244-250.

DYCE, Alexander. Introduction and notes. In: KEMP, William. Nine Daies Wonder: Performed in a daunce from London to Norwich. London: Camden Society, 1839, p. V-XXVII. Disponível em: <http:// www.gutenberg.org/files/21984/21984h/21984-h.htm>. Acesso em: 19 abr. 2017.

FURNESS, Horace Howard. A New Variorum Edition of Shakespeare: Hamlet. New York: Dover Publications, 1871.

FURNIVALL, Frederic. The New Shakspere Society's Transactions. Michigan: Trübner \& Company, 1880.

GAYLEY, Charles Mills. An Historical View of the Beginnings of English Comedy. GAYLEY, Charles Mills (ed). Representative English Comedies: From the Beginnings to Shakespeare. London: Macmillan \& Co, LTD, 1903, p. xi-xcii.

HALES, John Wesley. Notes and Essays on Shakespeare. London/New York: 1892.

HAWKESWORTH, John. Prologue to Oroonoko alter'd. In: SOUTHERNE, Thomas. Plays written by Thomas Southerne with An Account of the life and writings. Vol 1. Oxford: Oxford University School of English, 1774, p. 8.

JOHNSON, Samuel. Dr. Johnson's Preface. In: MALONE, Edmond. The Plays and Poems of William Shakspeare: Prolegomena. Volume 1, Part 1. London: H. Baldwin, 1790, p. 1-49.

KEMPE, William. In: LEE, Sidney (ed). Dictionary of National Biography. 1.ed. New York/London: MacMillan/Smith and Elder, 1892. Vol. XXX: JOHNNES KENNETH, p. 390-394. Disponível em: <https://archive.org/stream/dictionarynatio54stepgoog\#page/n400/mode/2u p >. Acesso em: 16 nov. 2018.

LESSING, Gotthold Ephraim. Hamburgische Dramaturgie. Michigan: University of Michigan Library, 1890.

LOUNSBURY, Thomas. Shakespeare as a Dramatic Artist: with an account of his reputation at various periods. New York: Charles Scribner's Sons, 1908.

MILTON, John. Samson Agonistes. In: MILTON, John. Paradise regain'd: a poem in IV books to which is added Samson Agonistes. London: Printed by J[ohn]. M[acock]. for John Starkey at the Mitre in Fleestreet, near Temple-Bar, 1671, p. 9- 101.

RYMER, Thomas. From the Tragedies of the Last Age: consider'd and examin'd by the practice of the Ancients and by the common sense of all ages (1678). In: SPINGARN, Joel Elias. Critical Essays of the 17 $7^{\text {th }}$ Century, Oxford: Clarendon Press, 1908, p. 181-208.

SCHELLING, Felix Emanuel. English Literature During the Lifetime of Shakespeare. New York: H. Holt, 1910.

SIMPSON, Richard. School of Shakespeare. London: Chatto and Windus, 1878.

STOLL, Elmer Edgar. John Webster: The Periods of His Work as Determined by His Relations to the Drama of His Day. 1905.

THÜMMEL, Julius Sigismund. Ueber Shakespeare's Clowns, Shakespeare-Jahrbuch, vol. 11, p. 78-96, 1876.

VOLKELT, Johannes. Ästhetitk des Tragischen. Munchen: Beck, 1897. 
WENDELL, Barrett. William Shakespeare: a study in Elizabethan literature. New York: Charles Cribner's Sons, 1912.

WHETSTONE, George. The Dedication to Promos and Cassandra. In: SMITH, George Gregory. Elizabethan Critical Essays. Vol I. London: Oxford University Press, 1904, p. 46-57.

\section{Traduções}

KYD, Thomas. Tragédia Espanhola. Tradução de Bárbara Heliodora. In: HELIODORA, Bárbara (org). Dramaturgia Elizabetana. Coleção Textos 33. São Paulo Perspectiva: 2015, p. 39-166.

MAETERLINCK, Maurice. Peleas e Melisanda. Tradução de Cecília Meireles. Rio de Janeiro: Arquivo do Instituto de Manuscritos da Biblioteca Nacional, 1944.

MARLOWE, Christopher. Tamerlão. Tradução de Bárbara Heliodora. In: HELIODORA, Bárbara (org). Dramaturgia Elizabetana. Coleção Textos 33. São Paulo: Editora Perspectiva, 2015, p. 179-267.

. A Trágica História do Doutor Fausto. Tradução de Bárbara Heliodora. In: HELIODORA, Bárbara (org). Dramaturgia Elizabetana. Coleção Textos 33. São Paulo: Editora Perspectiva, 2015, p. 271-340.

PLUTARCO. Vidas Paralelas. Volume IX - Marco Bruto. Disponível em: <http://www.consciencia.org/marco-junio-bruto-plutarco > Acesso em 18 abr. 2017.

SHAKESPEARE, William. Júlio Cesar. Tradução de Carlos Alberto Nunes. Coleção Obras Completas de Shakespeare. Volume IX - Tragédias: Antônio e Cleópatra e Júlio César. São Paulo: Melhoramentos, 1958. Antônio e Cleópatra. Tradução de Carlos Alberto Nunes. Coleção Obras Completas de Shakespeare. Volume IX - Tragédias: Antônio e Cleópatra e Júlio César. São Paulo: Melhoramentos, 1958.

. Romeu e Julieta. Tradução de Bárbara Heliodora. Rio de Janeiro: Lacerda Editores, 1997. 2008. . Tito Andrônico. Tradução de Carlos Alberto Nunes. Rio de Janeiro: Agir, 